\title{
Outcomes of Instrumented Posterolateral Fusion for Patients Over 70 Years with Degenerative Lumbar Spinal Disease: A Minimum of 2 Years Follow-up
}

\author{
Mong Lee ${ }^{1}$, Hee-Jin Yang ${ }^{2}$, Sang Hyung Lee ${ }^{2}$, Sung Bae Park ${ }^{2}$ \\ ${ }^{I}$ Department of Neurosurgery, Inje University College of Medicine, Seoul Paik Hospital, Seoul, \\ ${ }^{2}$ Department of Neurosurgery, Seoul National University College of Medicine, Boramae Medical Center, Seoul, Korea
}

\begin{abstract}
Objective: To determine the outcome of posterolateral fusion (PLF) for patients over 70 years of age with degenerative lumbar spinal disease.

Methods: The authors reviewed 18 patients ( 13 women and 5 men) over 70 years of age who underwent PLF with a minimum 2-years follow-up at a single institution. The parameters for analysis were clinical outcome, intraoperative bleeding, operating time, transfusion amount, fusion rate, decreased disc height at the operated level, and the incidence of adjacent disc degeneration.

Results: The mean age and follow-up duration were 74.1 years and 44.7 months, respectively. The mean fusion level was 2.5 levels. 12 patients (66.7\%) reported good or excellent outcomes, and 4 patients complained of poor outcomes. The fusion rate was $61.1 \%$. The rate of adjacent segment degeneration was $61.1 \%$. Among all of the patients, 5 had decreased intervertebral disc heights compared to their initial statuses. In correlative comparison analyses of parameters, a significant correlation was observed between a "good" or better clinical outcome and fusion $(p=0.034)$. Also, there were significant relationships between a "fair" or better clinical outcome and fusion $(p=0.045)$ and decreased disc height at the operated level $(p=0.017)$. Other factors did not have a significant relationship with the clinical outcome.

Conclusions: Before performing instrumented PLF in patients over 70 years old, problems related to the low fusion rate and adjacent segment degeneration should be considered and relevant information should be provided to the patients and the family.
\end{abstract}

Key Words: Aged $\cdot$ Spine $\cdot$ Lumbar Vertebrae

\section{INTRODUCTION}

Lumbar fusion is a procedure for treatment of degenerative lumbar disease, as a degenerated and mobile lumbar segment could lead to pain ${ }^{8)}$. Additionally, lumbar fusion operations, such as instrumented posterolateral fusion (PLF) and posterior lumbar interbody fusion (PLIF), can provide patients suffering from chronic low back pain and radiculopathy with a reduction in pain and decreased disability ${ }^{14)}$. PLF has a long history

- Received: February 9, 2012 - Revised: June 21, 2012

- Accepted: June 22, 2012

Corresponding Author: Sung Bae Park, MD

Department of Neurosurgery, Seoul National University Boramae Medical

Center, 39 Boramae Road, Dongjak-gu, Seoul 156-707, Korea

Tel: +82-2-870-2302, Fax: +82-2-870-3863

E-mail: ddolbae01@naver.com and has been considered to be safe and effective ${ }^{16}$.

Although the fusion rate of PLF is below that of PLIF, PLF might prevent the development of adjacent segment degeneration (ASD) $)^{6}$. Additionally, PLF has the advantages of lower risk of complications such as lumbar root injury and dura laceration and is less technically demanding ${ }^{7,12,15)}$. Elderly patients have a low quality of bone compared to younger patients. Therefore, in instrumentation with elderly patients, screw loosening and low fusion rates have been problems. However, many studies have indicated that lumbar fusion surgery in elderly patients resulted in successful fusion clinical outcomes, ${ }^{2,10,)}$. Although many studies have demonstrated the clinical and radiological results of instrumented PLF in young patients or across all age groups, relatively few articles have been published about the radiological and clinical outcomes of elderly patients ${ }^{17,20)}$. Therefore, we studied the outcomes of instrumented PLF in patients over 70 years of age with lumbar degenerative disease. 


\section{MATERIAL AND METHODS}

\section{Study population}

We retrospectively reviewed the charts and radiographs of patients over 70 years of age who were treated with instrumented PLF of the lumbar spine at a single institute from January 2000 to January 2009. Only 18 patients were selected according to the following criteria: (1) the patients were diagnosed with degenerative lumbar disease, such as spinal stenosis, degenerative disc disease, and lytic or degenerative spondylolisthesis, and (2) the durations of radiological and clinical follow-ups were more than 24 months. The mean age of the enrolled patients was 74 years (70-78). Five patients were male, and 13 patients were female. The postoperative mean followup period was $44.7 \pm 15.67$ months (25-73). All of the patients underwent total laminectomy at the lesion level, and then pedicle screw fixation and posterolateral bone grafting using autologous bone materials.

\section{Parameters considered in assessing outcomes}

Functional outcome was assessed by Kirkaldy-Willis criteria $(\text { Table } 1)^{20)}$. We analyzed late follow-up functional outcomes, and complications were assessed at each follow-up visit. Clinical parameters, including functional outcomes and complications, were operating time, bleeding amount during surgery, wound infection, pneumonia, respiratory distress, and deep vein thrombosis.

Radiological assessment was evaluated by the fusion rates and adjacent segment degeneration (ASD) at the time of the last follow-up. The posterolateral fusion was graded by the method of Lenke et al. as follows: Grade A, definitely solid with bilateral trabeculated stout fusion masses present; Grade $\mathrm{B}$, possibly solid with a unilateral large fusion mass and a contralateral small fusion mass; Grade C, probably not solid with a small fusion mass bilaterally; Grade D, definitely not solid with bone graft resorption or obvious pseudoarthrosis bilaterally ${ }^{11)}$. Also, more than 4 degrees of motion between the fusion segments in dynamic radiographs was considered to be a fusion failure. Therefore, the segment rated grade $\mathrm{C}$ or higher and with less than 4 degrees of motion in dynamic view was considered to have a solid fusion.

Additionally, the development of new spondylotic changes in the adjacent vertebral bodies or aggravated or newly developed degenerative disc disease and spondylolisthesis in the adjacent level or a decrease of more than $10 \%$ in the height of the adjacent discs was considered to indicate ASD.

We analyzed the significance of the relationships among sex, age, fusion, clinical outcome, ASD, and decreased disc height.

\section{Statistical analysis}

The Student's t-test and Fisher's exact test were used for statistical analysis. $\mathrm{p}<0.05$ was considered statistically significant. Pearson's correlation was used to evaluate the statistical significance of several parameters.

\section{RESULTS}

The majority of primary diagnoses were lumbar spinal stenosis. The mean operating time and volume of intraoperative bleeding were 202.8 \pm 37.82 minutes (155-320) and 952.0 \pm $289.53 \mathrm{cc}(820-1500)$, respectively. Three of the patients underwent lumbar discectomy during instrumented PLF. The mean fusion level was $2.5 \pm 0.783$ levels, and the L4-5 level was the most commonly fused segment (Table 2).

Table 1. Kirkaldy-Willis criteria

\begin{tabular}{|c|c|}
\hline Criteria & Contents \\
\hline Excellent & $\begin{array}{l}\text { The patient has returned to his normal work and } \\
\text { other activities with little or no complaint }\end{array}$ \\
\hline Good & $\begin{array}{l}\text { The patient has returned to his normal work but } \\
\text { may have some restriction in other activities and } \\
\text { may, occasionally after heavy work, have } \\
\text { recumbent, back pain requiring a few days' rest }\end{array}$ \\
\hline Fair & $\begin{array}{l}\text { The patient has reduced his working capacity } \\
\text { taking a lighter job or working part-time, } \\
\text { requiring absence from work for one to two } \\
\text { weeks, once of twice of year }\end{array}$ \\
\hline Poor & The patient does not return to work \\
\hline
\end{tabular}

Table 2. Characteristics of the study population

\begin{tabular}{lc}
\hline \hline Parameters & \\
\hline Sex (female/male) & $13 / 5$ \\
Age at operation (years) & $74.1 \pm 2.64$ \\
Follow-up duration (months) & $44.7 \pm 15.67$ \\
Operation time (months) & $202.8 \pm 37.82$ \\
Blood loss (mL) & $925.0 \pm 289.53$ \\
Operated level & $2.5 \pm 0.783$ \\
Primary diagnosis & \\
$\quad$ stenosis & 12 \\
Disc disease & 3 \\
spondylolisthesis & 3 \\
\hline
\end{tabular}


Among the 18 patients, 12 patients (66.7\%) mentioned good or excellent outcomes, while 4 patients (22.2\%) complained of a poor outcome. Only 2 patients (11.1\%) described their symptoms as fair. The patients with poor outcomes complained of persistent back pain, difficulties in sitting, and persistent leg weakness. These symptoms were not related to surgical procedures such as instrumented PLF. Additionally, no wound infection, pneumonia, respiratory distress, or deep vein thrombosis were observed during hospitalization or during the follow-up period.

In the assessment of radiological outcomes, the number of patients rated grade A, B, C, and D were 4 (22.2\%), 3 (16.7\%), $7(38.9 \%)$, and $4(22.2 \%)$, respectively. Among the patients with grade $\mathrm{C}$ or higher, only 11 patients had less than 4 degrees of motion. Therefore, the fusion rate was $61.1 \%(11 / 18$ patients). Until the last follow-up period, the incidence of ASD was $61.6 \%$ (11/18 patients). However, no additional operations were performed due to the ASD. Follow-up radiography showed that 5 patients $(27.8 \%)$ had decreased disc height at the index level. Among the 4 patients with poor outcomes, 3 patients had decreased disc heights at the index level. One patient had junctional kyphosis in follow-up radiography. However, the patient had no complaints of back pain. One case presented with a rod fracture in follow-up radiography (Fig. 1).

In a correlation study between the radiological and functional outcomes including bridging bone formation, decreased disc height, fusion, fused level, and clinical outcomes, a significantly positive correlation was seen between clinical outcome and fusion $(\mathrm{p}=0.034)$.

Also, there were significant relationships in the comparison between "fair" and better clinical outcomes and fusion $(\mathrm{p}=$ $0.045)$ and decreased disc height at the operated level $(p=$ 0.017). The fusion level had no significant relationship with the operating time, bleeding amount, fusion rate, clinical outcome, or ASD. Other factors including age, operating time, bleeding amount, the decreased disc height, fusion level, and ASD did not have a significant relationship with the clinical outcome.

\section{DISCUSSION}

This study indicated that the fusion rate of elderly patients over 70 years who underwent instrumented PLF in the lumbar spine was $61.6 \%$, and among all of the 18 patients, 12 (66.7 $\%)$ had good or excellent clinical outcomes. Four patients com plained of poor clinical outcomes. The incidence of ASD was $61.6 \%$ (11/18 patients). However, no surgically-related complications occurred.
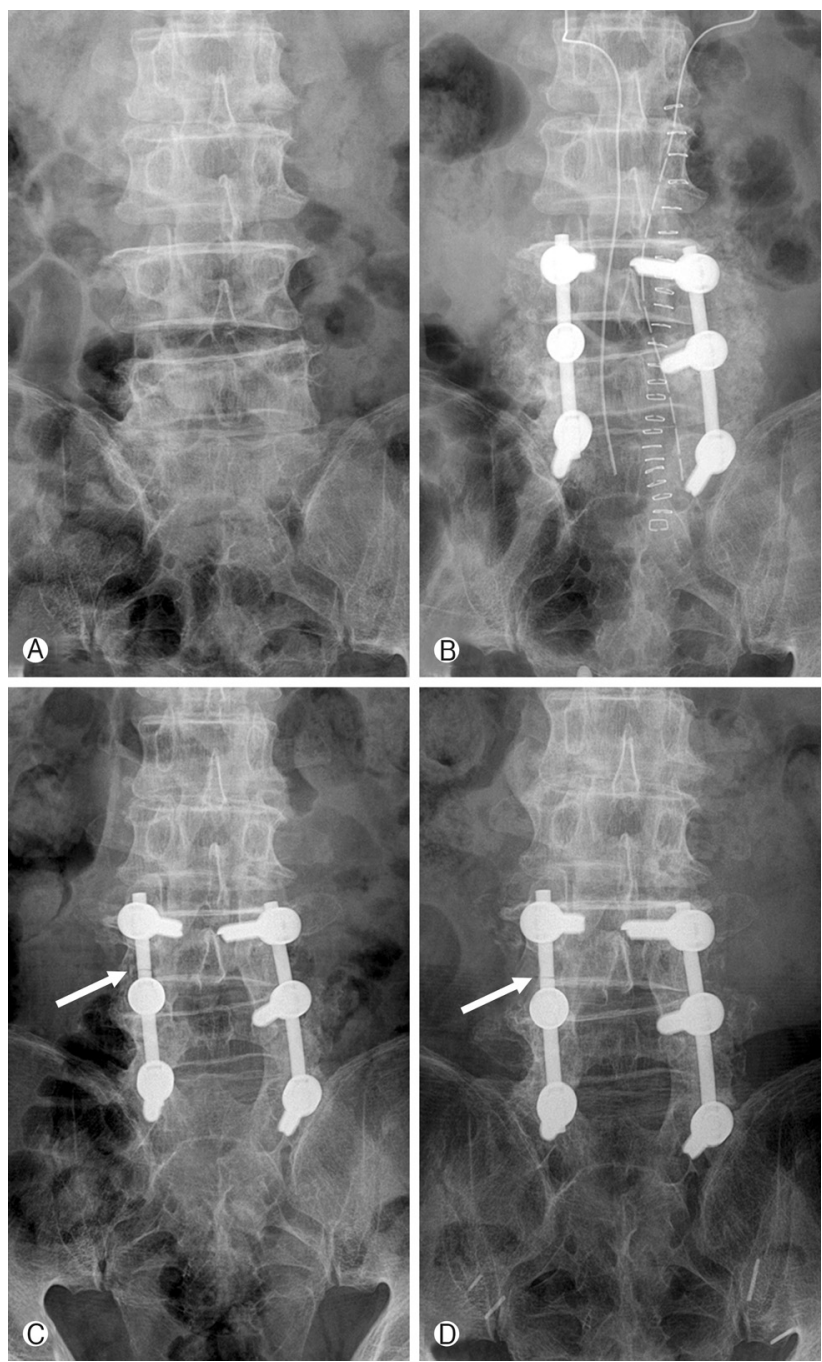

Fig. 1. Case of the rod fracture. This picture shows the X-ray radiographies of patient with rod fracture (arrow) at preoperative (A), immediately postoperative (B), two year follow-up postoperative (C), and four year-follow up postoperative periods (D).

Studies on PLF in the lumbar spine have reported an inferior fusion rate compared with that of $\mathrm{PLIF}^{5,7}$. Anterior support in PLIF is undoubtedly superior to that in PLF"). However, PLF is a more familiar technique than PLIF to some spine surgeons. Another advantage of PLF is a lower risk of complications, and many studies have noted that no significant differences in operating time, complication rates, blood loss, or clinical outcomes were observed between instrumented PLF and instrumented PLIF ${ }^{7,15,19)}$. Therefore, the PLF technique may be an alternative approach for elderly patients who have more surgical risks than younger patients.

In many studies, the patients over 65 years of age who underwent lumbar fusion surgery had successful clinical outcomes $^{2,3,10)}$. A study on the quality of life after PLF in patients 
over 75 years of age indicated good functional outcomes at 2 years after lumbar arthrodesis, and advanced age should not be considered a contraindication to $\mathrm{PLF}^{4)}$. Although three patients in this study underwent bone mineral density measurement by DEXA scan for screw fixation, other studies have emphasized preoperative evaluation of bone mineral density because osteoporosis can induce pseudarthrosis, screw loosening, and adjacent vertebral fracture ${ }^{1,18)}$. In this study, no screw loosening occurred, and one rod fracture was observed during the follow-up period. Several reports have presented the beneficial effects of instrumentation in elderly patients who underwent lumbar fusion surgery ${ }^{2,13)}$. Instrumented PLF in elderly patients may have comparable clinical outcomes to instrumented interbody fusion.

In this study, the mean fusion level was 2.5 (2-level fusion: 10 patients, 3-level fusion: 7 patients, and 5-level fusion: 1 patient). There was no significant relationship between the fusion level and other parameters such as fusion rate, ASD, or clinical outcome. The main cause of this result may be the small number of patients.

This study had several limitations, such as its retrospective nature, lack of a comparative study design, and a small sample size. Without a comparison between PLF and PLIF, we are not able to suggest clear guidelines on the proper application of instrumented PLF to elderly patients. Furthermore, in elderly patients, bone mineral density is a risk factor for decreased fusion. That only four patients underwent bone mineral density measurement pre- or post-operatively is another limitation of the study. Further studies with randomized, prospective designs and large sample sizes are required to more precisely evaluate the advantages and disadvantages of instrumented PLF in the lumbar spine of elderly patients.

\section{CONCLUSION}

In this study, no surgically related complications or perioperative death were seen in patients over 70 years old who underwent instrumented PLF in the lumbar spine. However, before instrumented PLF is performed in patients over 70 years of age, problems related to the low fusion rate and ASD should be considered and information on these risks should be provided to patients and their families.

\section{REFERENCES}

1. Andersen T, Christensen FB, Niedermann B, Helmig P, Hoy $\mathrm{K}$, Hansen ES, et al: Impact of instrumentation in lumbar spinal fusion in elderly patients: 71 patients followed for 2-7 years. Acta Orthop 80:445-450, 2009
2. Barrick WT, Schofferman JA, Reynolds JB, Goldthwaite ND, McKeehen M, Keaney D, et al: Anterior lumbar fusion improves discogenic pain at levels of prior posterolateral fusion. Spine (Phila Pa 1976) 25:853-857, 2000

3. Crawford $\mathrm{CH}$, 3rd, Smail J, Carreon LY, Glassman SD: Health-related quality of life after posterolateral lumbar arthrodesis in patients seventy-five years of age and older. Spine (Phila Pa 1976) 36:1065-1068, 2011

4. Fraser RD: Interbody, posterior, and combined lumbar fusions. Spine (Phila Pa 1976) 20 Suppl:167S-177S, 1995

5. Fischgrund JS, Mackay M, Herkowitz HN, Brower R, Montgomery DM, Kurz LT: 1997 Volvo Award winner in clinical studies. Degenerative lumbar spondylolisthesis with spinal stenosis: a prospective, randomized study comparing decompressive laminectomy and arthrodesis with and without spinal instrumentation. Spine (Phila Pa 1976) 22:2807-2812, 1997

6. Glassman SD, Carreon LY, Dimar JR, Campbell MJ, Puno RM, Johnson JR: Clinical outcomes in older patients after posterolateral lumbar fusion. Spine J 7:547-551, 2007

7. Han X, Zhu Y, Cui C, Wu Y: A meta-analysis of circumferential fusion versus instrumented posterolateral fusion in the lumbar spine. Spine (Phila Pa 1976) 34:E618-625, 2009

8. Helenius I, Lamberg T, Osterman K, Schlenzka D, Yrjonen T, Tervahartiala P, et al: Posterolateral, anterior, or circumferential fusion in situ for high-grade spondylolisthesis in young patients: a long-term evaluation using the Scoliosis Research Society questionnaire. Spine (Phila Pa 1976) 31:190-196, 2006

9. Kirkaldy-Willis WH, Paine KW, Cauchoix J, McIvor G: Lumbar spinal stenosis. Clin Orthop Relat Res 99:30-50, 1974

10. Kornblum MB, Fischgrund JS, Herkowitz HN, Abraham DA, Berkower DL, Ditkoff JS: Degenerative lumbar spondylolisthesis with spinal stenosis: a prospective long-term study comparing fusion and pseudarthrosis. Spine (Phila Pa 1976) 29: 726-733, 2004

11. Lenke LG, Bridwell KH, Bullis D, Betz RR, Baldus C, Schoenecker PL: Results of in situ fusion for isthmic spondylolisthesis. J Spinal Disord 5:433-442, 1992

12. Madan S, Boeree NR: Outcome of posterior lumbar interbody fusion versus posterolateral fusion for spondylolytic spondylolisthesis. Spine (Phila Pa 1976) 27:1536-1542, 2002

13. Okuyama K, Abe E, Suzuki T, Tamura Y, Chiba M, Sato K: Influence of bone mineral density on pedicle screw fixation: a study of pedicle screw fixation augmenting posterior lumbar interbody fusion in elderly patients. Spine J 1:402-407, 2001

14. Ragab AA, Fye MA, Bohlman HH: Surgery of the lumbar spine for spinal stenosis in 118 patients 70 years of age or older. Spine (Phila Pa 1976) 28:348-353, 2003

15. Tajima N, Chosa E, Watanabe S: Posterolateral lumbar fusion. J Orthop Sci 9:327-333, 2004

16. Totoribe K, Tajima N, Chosa E: A biomechanical study of posterolateral lumbar fusion using a three-dimensional nonlinear finite element method. J Orthop Sci 4:115-126, 1999

17. Wee SB, Jung SS, Park KS, Kun SU: Surgical treatment of degenerative lumbar spine disease in geriatric patients over 70 years old: a review of two decades. Korea J Spine 5:161166, 2008 
18. Wu CH, Kao YH, Yang SC, Fu TS, Lai PL, Chen WJ: Supplementary pedicle screw fixation in spinal fusion for degenerative spondylolisthesis in patients aged 65 and over: outcome after a minimum of 2 years follow-up in 82 patients. Acta Orthop 79:67-73, 2008

19. Yajun W, Yue Z, Xiuxin H, Cui C: A meta-analysis of artificial total disc replacement versus fusion for lumbar degenerative disc disease. Eur Spine J 19:1250-1261, 2010

20. Zhou ZJ, Zhao FD, Fang XQ, Zhao X, Fan SW: Meta-analysis of instrumented posterior interbody fusion versus instrumented posterolateral fusion in the lumbar spine. J Neurosurg Spine 15:295-310, 2011 